INDEPENDENT JOURNAL OF MANAGEMENT \& PRODUCTION (IJM\&P)

http://www.ijmp.jor.br

v. 6 , n. 1, January - March 2015

ISSN: 2236-269X

DOI: 10.14807/ijmp.v6i1.247

\title{
AN APPLICATION FOR EFFICIENT TELECOMMUNICATION NETWORKS PROVISIONING USING LINEAR PROGRAMMING
}

\author{
Maria Augusta Soares Machado, \\ IBMEC-RJ, Brazil \\ E-mail: mmachado@ibmecrj.br \\ Walter Gassenferth \\ IBMEC-RJ, Brazil \\ E-mail: walterg@quantiac.com
}

Submission: $17 / 06 / 2014$

Revision: 02/07/2014

\section{ABSTRACT}

Accept: 07/07/2014

This paper presents a practical proposition for the application of the Linear Programming quantitative method in order to assist planning and control of customer circuit delivery activities in telecommunications companies working with the corporative market. Based upon data provided for by a telecom company operating in Brazil, the Linear Programming method was employed for one of the classical problems of determining the optimum mix of production quantities for a set of five products of that company: Private Telephone Network, Internet Network, Intranet Network, Low Speed Data Network, and High Speed Data Network, in face of several limitations of the productive resources, seeking to maximize the company's monthly revenue. By fitting the production data available into a primary model, observation was made as to what number of monthly activations for each product would be mostly optimized in order to achieve maximum revenues in the company. The final delivery of a complete network was not observed but the delivery of the circuits that make it up, and this was a limiting factor for the study herein, which, however, brings an innovative proposition for the planning of private telecommunications network provisioning.

Keywords: Linear Programming Method, Telecommunication Networks, Provisioning. 


\section{INTRODUCTION}

In the past few years telecommunications have become an input of great business importance, especially for large companies. The need for their own telecommunications network provisioning has been a constant concern of large- and medium-sized enterprises the world over. Even when a large telecommunications company is outsourced to operate a customer's network, the circuits provisioning of that network is of utmost importance for the continuation of the business regarding time and quality.

Upon delivery of circuits to customers, the large telecom network providers seek ways to reduce their costs by relying on smaller teams and even more reduced delivery schedules in an attempt to meet the customer's needs before their competitors do. A data communication network provisioning, for instance, which in 1999 was activated in 45 days by Europe's biggest players, BTI, and by U.S.A.'s $\mathrm{MCl}$, nowadays is prepared and delivered to the customer in 21 to 25 days (YANKEE GROUP, 2005). However, these are average schedules since urgent activations are special cases that can be delivered in less than a week.

In Brazil the telecommunications industry is facing a scenario with an excessive number of telecom service providers, with an overestimated demand that marks a scenario of hyper-competition. Thus, the briefness in activating a service overcomes all of the other features of that service provisioning, also putting aside an adequate planning of delivery of the products that make up the customer's network and this prioritization of delivery brings about some loss to the service provider's cash.

This paper, which is based on data provided by one telecom provider in Brazil, presents an essay that aims to propose a simple alternative, yet with a solid mathematical basis, in order to ensure there is a marker in the prioritization of customers' circuit provisioning that aims at the main goal of sales and the business: its profitability.

\section{CIRCUIT ACTIVATIONS IN TELECOM COMPANIES}

In order to better understand the proposition of this paper, one must get to know a little about the activation or delivery process of a telecommunications network provisioning. This network, presented in Figure 1, is a set of circuits interlocking 
DOI: 10.14807/ijmp.v6i1.247

through a large telecom operator backbone several customer environments (sites), from which he operates his business.

This process includes all the activities from the request of a service order by the customer to the provisioning of the network in operation (the beginning of its commercial running), going through assembly of every physical part of the network, the configuration of its logical parameters, and the running test with customer's application, simulating the day-to-day of the business as shown in Figure 2.

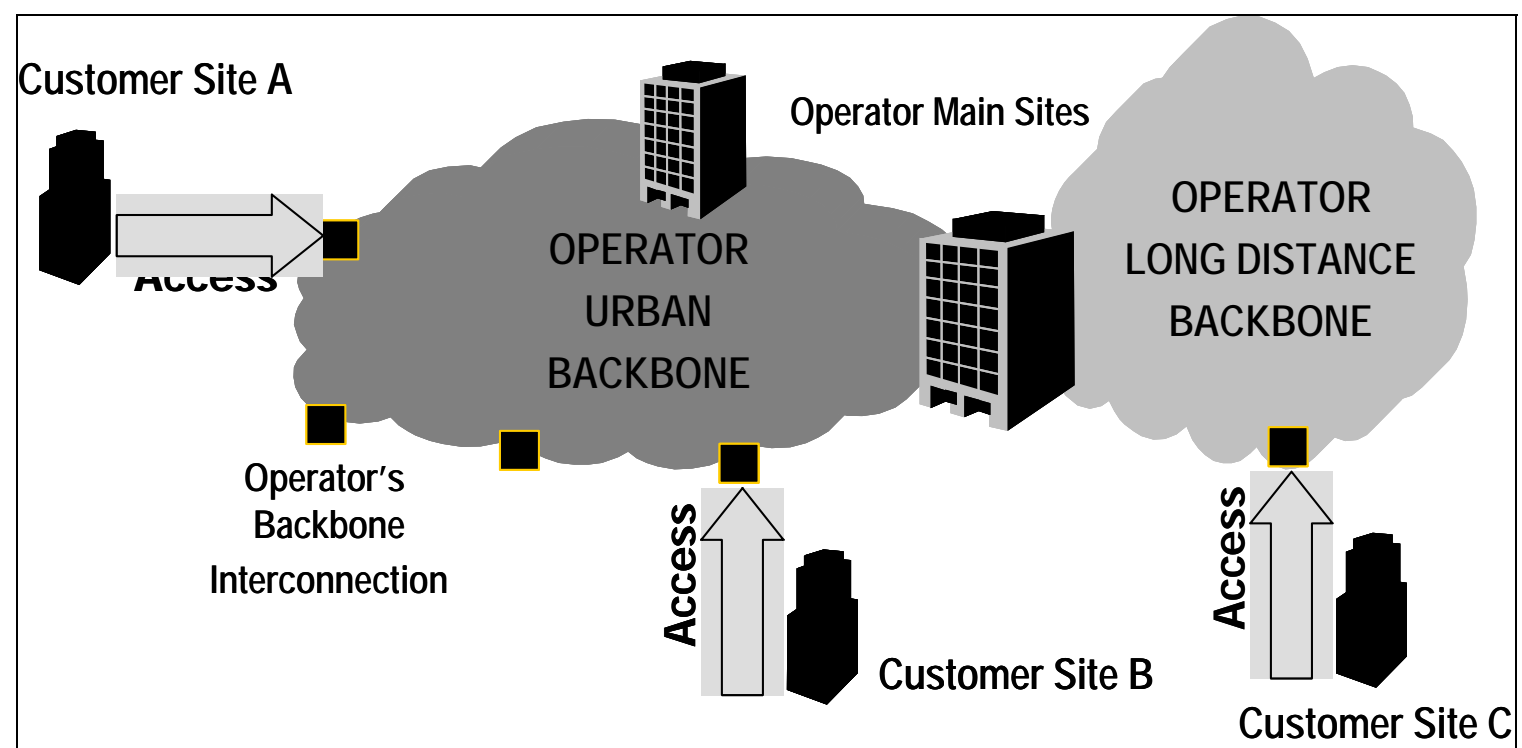

Figure 1 - Diagram representing a Customer Network Provisioning set up from the backbone of a large telecom operator.

In Figure 2, it can also be noticed that within the assembly of the backbone's physical part the local access granting activities (2), also known as 'last mile'; equipment acquisition activities for installation at customers' sites (4); facility allocation activities (communication channels to be used in the customer's network) within the operator's large backbone (1); and customer's network configuration (3) are all capital availability activities of fundamental importance in order to ensure activation of all the circuits making up the customer's network provisioning. 
DOI: 10.14807/ijmp.v6i1.247

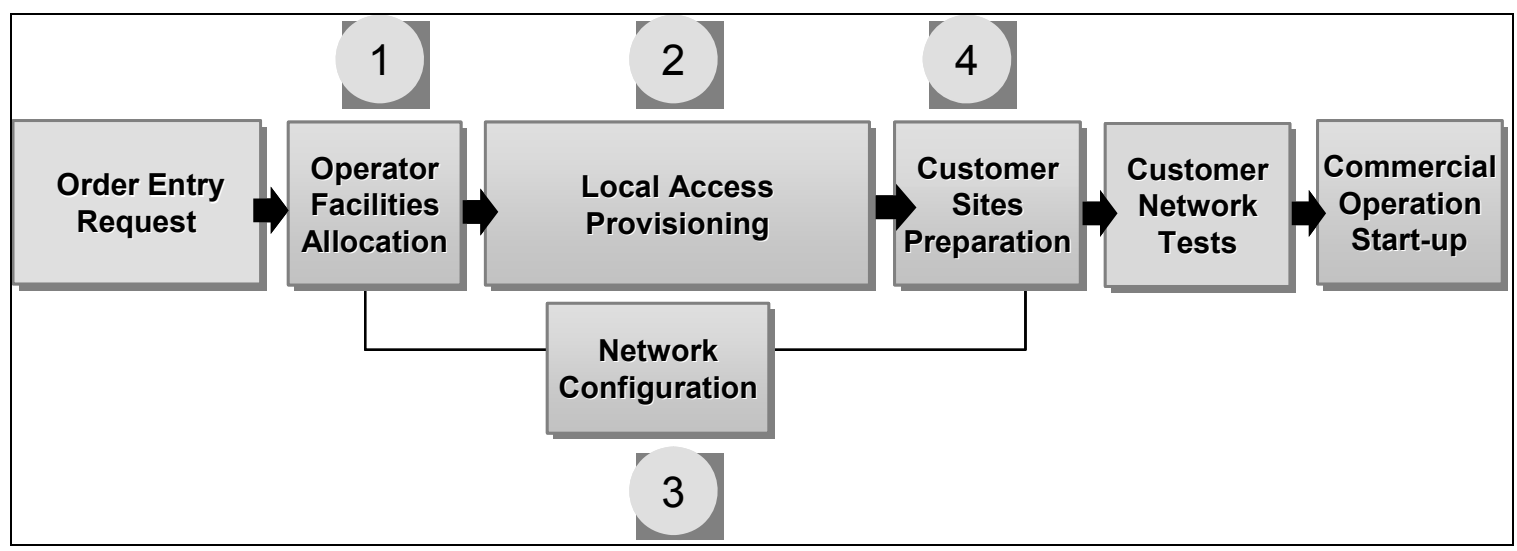

Figure 2 - Simplified representation of the Customer Network Provisioning Process of a large telecom operator in Brazil.

The lack, or poor distribution, of such capital brings about a delay in the provisioning of the networks, resulting in loss of profit to the telecom operator. Moreover, the random allocation, as in a line-up system - FIFO - First In First Out, or simply proportional to the resources available, might bring about an undesired delay effect on large capital inflow to the operator, thus representing a problem that can be solved in a structured way through a Linear Programming Model.

\section{THE LINEAR PROGRAMMING MODEL PROPOSED}

The operational research is a mathematical method developed to solve problems related to tactical and strategic operations. Its origins show its application in the decision-making process of business analysis, mainly regarding the best use for short funds. This shortage of funds is a characteristic of hyper-competitive environments. Although the practical application of a mathematical model is wide and complex, it will provide a set of results that enable the elimination of a part of the subjectivism that exists in the decision-making process as to the choice of action alternatives (BIERMAN and BONINI, 1973).

One important feature of the operational research that greatly benefits analysis and decision is the use of models. The models allow for experiments to be conducted and this means that the decision may be further tested and evaluated before final decision and, therefore, before preparation and implementation of any solution through planning and action (ACKOFF, 1976).

It is clear that the study of a real system has a certain degree of complexity since it is influenced by a number of elements or variables and also by both internal 
DOI: 10.14807/ijmp.v6i1.247

and external social, political and economic matters. The characteristics of the decision-making process will have great influence on determining and utilizing models. One model consists of the representation of reality through variables that allow for solving a given problem. Ackoff and Sasieni (1971) classify problems in three kinds:

a) Iconical: those models dealing with the representation of images in a different scale from the actual object of study like, for example, aircraft, ships and automobiles models;

b) Analogical: these make use of a set of properties in order to represent another set of properties like, for example, the graphs that make use of geometrical greatness and positions in order to represent many types of variables and their relationships;

c) Symbolical: these represent the variables and their relationship through letters, numbers and other types of symbols; they are general and abstract models, normally presented like mathematical relations and reflect the structure of what they reproduce.

Therefore, the complexity of the decision-making process applied to business, in some cases, can be studied through operational research by means of symbolic models (CARASTAN, 1993).

The operational research can assist the decision-making process through the Linear Programming Model. This model is suitable for solving such problems as, for example, allocation of short funds in order to achieve a certain goal. Linear Programming deals with special mathematical problems by developing rules and relationships that aim at the distribution of limited funds under the restrictions imposed by either technological or practical aspects when an attribution decision has to be made (ANDRADE, 1990).

One type of problem for which the Linear Programming provides a solution could be summarized as: to maximize or to minimize any dependent variable which is a linear function of several independent variables which are subject to many restrictions (CARLSON, 1988). 
DOI: 10.14807/ijmp.v6i1.247

Example: profit maximization, return on investment, sales, cost reduction, machine-hour, size of material inventories etc.

In order to solve problems through the proposed model, structuring of a general formulation is required.

The problems dealt with here refer to the optimization of resources of a given object function "f", which is subject to system and/or environment restrictions. When the problem involves " $n$ " decision-making variables and " $m$ " restrictions, the model can be represented mathematically in the form of either maximization or minimization of the object function (CORRAR and TEÓPHILO, 2003; ZUMA V., CALDEIRA, A. M., PACHECO, G. L., MACHADO, M. A.S., GASSENFERTH, W., 2008). For instance, for a maximization problem:

MAXIMIZE Z $=C 1 X 1+C 2 X 2+\ldots+C n X n$

Subject to restrictions:

a $11 X 1+a 12 X 2+\ldots+a 1 n X n \leq b 1$

$a 21 X 1+a 22 X 2+\ldots+a 2 n X n \leq b 2$

$a m 1 X 1+a m 2 X 2+\ldots+a m n X n \leq b m$

Being compulsory that:

$X 1, X 2, \ldots, X n \geq 0$ (note: non-negative figures)

\section{THE HYPER-COMPETITION CONCEPT}

The application of linear programming models is recommended in production environments, especially in companies that are faced with a scenario of hypercompetition supporting the decision-making process. Hyper-competition consists of an environment marked by fast and intense competitive movements in which aggressive, innovative flexible competitors invade the market to build up advantages and destroy their opponents' position. The approach focused in the hyper-competitive environment is made up of the rupture of the "status quo", thus creating a number of temporary advantages (D'AYENI, 1995).

The hyper-competitive behavior creates, continuously, new competitive advantages that render obsolete or neutralize the opponent's competitive advantage, create inequality and destroy perfect competition, thus breaking market equilibrium. 
DOI: 10.14807/ijmp.v6i1.247

Hyper-competition takes place in a world of complex dynamics, where players interact at world level, where competitive advantages are ephemeral and the life cycle of products is short, unstable and, in many cases, unpredictable. In this context of permanent instability, survival becomes a function of the ability to interact associatively with suppliers, customers and competitors. And so arises the need for organizational networks that aim to reduce uncertainties and risks and to organize economical activities through the coordination and cooperation among companies.

As for the internal plan, organizations need to work in a more optimized fashion by reducing their costs and maximizing their earnings by means of revenue anticipation, for instance. The mathematical models become of utmost importance in supporting productive activities and aiming at a higher efficiency of the operating processes and greater support to the tactical, immediate decisions, causing this type of organization to have a continuous evolution, which is fundamental in a hypercompetition market. The telecommunications market, especially in Brazil, appears to have been in a hyper-competition situation for the past three years.

\section{THE CASE OF THE BRAZILIAN TELECOM COMPANY}

The customer network provisioning division of a big telecommunications company in the Brazilian market activates on a monthly basis 3,000 circuits of different products (types of network), which are offered to the market in the following categories: Private Telephone Network, Internet Network, Intranet Network, Low Speed Data Network, and High Speed Data Network. Its limited capital and output capacity allow it to activate only $35 \%$ out of the 8,500 circuit's backlog monthly.

This does not pose a problem for the customers since they accept delivery of their networks in up to 60 days depending upon the complexity of the network and the kind of business it is intended for. However, since the prices charged for the circuits in each kind of network are different, the company expects that priority be given to the activation of the circuits that represent higher earnings to the company. Nowadays, there is no indicator of how many circuits for each kind of product must be activated on average per month, so that guidance from the company's higher management can be followed.

So, in a typical month of 2004 , a survey was conducted as to the situation of the company's circuit delivery and the following results were attained: 
INDEPENDENT JOURNAL OF MANAGEMENT \& PRODUCTION (IJM\&P)

http://www.ijmp.jor.br

v. 6, n. 1, January - March 2015

ISSN: 2236-269X

DOI: 10.14807/ijmp.v6i1.247

Table 1: Table that summarizes Circuit Backlog (Circuit Delivery) per Service Backlog of a Brazilian Telecom Company in a typical month.

\begin{tabular}{|c|c|c|c|}
\hline SERVICE BACKLOG & Physical & Financial & $\begin{array}{l}\text { Price per } \\
\text { Circuit }\end{array}$ \\
\hline Private Telephony & 5042 & 7.793.181,34 & $1.545,65$ \\
\hline INTERNET & 816 & $1.514 .787,96$ & $1.856,36$ \\
\hline INTRANET & 668 & $297.265,57$ & 445,01 \\
\hline $\begin{array}{c}\text { Low Speed Data } \\
\text { Network }\end{array}$ & 1459 & $1.577 .497,01$ & $1.081,22$ \\
\hline $\begin{array}{c}\text { High Speed Data } \\
\text { Network }\end{array}$ & 543 & $810.431,96$ & $1.492,51$ \\
\hline Total & 8528 & $11.993 .163,84$ & $1.406,39$ \\
\hline
\end{tabular}

Where:

- Service Backlog: Circuit delivery orders for each product of the company;

- Physical Backlog: Number of telecommunications circuits to be delivered;

- Financial Backlog: Total revenue of the company after circuit activations (deliveries) (in R\$: 1 US $\$=R \$ 2,66 ; 1 R \$=U S \$ 0,375$ on Dec/30/2004);

- Price per Circuit: Average unit price of each circuit in each kind of network.

An attempt was made to understand the existing limitations to carry out circuit delivery in addition to the monthly production capacity, which is already estimated in 3,000 circuits per month without any additional work shift or engagement of temporary labor. Five main limiters were attained as well as their quantities that are required per month per type of product, as shown in Table 2 below. 
DOI: 10.14807/ijmp.v6i1.247

Table 2: Table that summarizes the required amount of each component that make up customer's circuits per type of service backlog.

\begin{tabular}{|c||r|r|r|r|r|}
\hline Type of Resource & PT & INTER & INTRA & \multicolumn{1}{|c|}{ LSD } & HSD \\
\hline \hline $\begin{array}{c}\text { Access (Last } \\
\text { Mile) }\end{array}$ & 998 & 162 & 132 & 289 & 108 \\
\hline $\begin{array}{c}\text { Equipment for } \\
\text { Customer's Sites }\end{array}$ & 1276 & 206 & 169 & 369 & 137 \\
\hline $\begin{array}{c}\text { Network } \\
\text { Facilities }\end{array}$ & 333 & 54 & 44 & 96 & 36 \\
\hline $\begin{array}{c}\text { Configuration of } \\
\text { Customer Network }\end{array}$ & 1477 & 239 & 196 & 428 & 159 \\
\hline Other Resources & 958 & 155 & 127 & 277 & 103 \\
\hline
\end{tabular}

Where:

Type of Resource: Part required for making up a customer's circuit: Access or Last Mile is the linking point between the customer's site and the operator's backbone; Equipment for the customers' sites are modems, routers or other equipment required for customer communication on each of his sites; Network Facilities are communications channels within the operator's backbone that carry customers' signals from one side of the country or the world to the other; Customer Network Configuration is a set of manual operations by a technician from the provider company in order to prepare the operator's backbone to allow traffic of the customer's network circuits through its facilities; Other Resources are a set of minor factors that have been grouped into a single item.

- PT: Private Telephone Networks;

- INTER: Internet networks;

- INTRA: Intranet Networks;

- LSD: Low Speed Data Networks;

- HSD: High Speed Data Networks.

Finally, the available amount of each limiting resource in a month was attained, from the physical viewpoint, as shown in Table 3 below. 
DOI: 10.14807/ijmp.v6i1.247

Table 3: Physical Limit Table for each resource required for Activations

\begin{tabular}{|c||r|}
\hline Type of Resource & $\begin{array}{c}\text { Limit for } \\
\text { each } \\
\text { Resource }\end{array}$ \\
\hline \hline $\begin{array}{c}\text { Access (Last } \\
\text { Mile) }\end{array}$ & 1200 \\
\hline $\begin{array}{c}\text { Equipment for } \\
\text { Customer's Sites }\end{array}$ & 1534 \\
\hline $\begin{array}{c}\text { Network } \\
\text { Facilities }\end{array}$ & 400 \\
\hline $\begin{array}{c}\text { Configuration of } \\
\text { Customer Network }\end{array}$ & 1776 \\
\hline Other Resources & 1152 \\
\hline
\end{tabular}

Based upon these data, the network activation division had to come up with a marker so that the selection of the circuits to have priority activation was favorable to the company's revenue formation, resulting from the greater amount of earnings as possible and considering the existing limitations.

\section{THE SOLUTION PROPOSED THROUGH A LINEAR PROGRAMMING MODEL}

What the company's higher management requires can be achieved through a simple linear programming model, which, unfortunately, is not used by any telecom company in Brazil despite the amount of engineers making up their staff. The model's automation is guaranteed through Microsoft Office's Excel application available in any of the telecom companies' PCs in Brazil.

In addition to the information made available by the company, only a calculation of the limit of activations in financial values is required for each set of resource limitations (access, equipment, network facilities, configurations and others). In order to achieve this, we considered that the maximum amount of activated circuits for each limiting resource, considered separately, is the limit figure for each resource. That is, for instance, if all resources were in abundance and access was limited to 1,200, as shown in Table 1, the maximum number of activated circuits would be 1,200 , equivalent in financial values to: $1200 \times 1406,57=R \$$ 1.687.884,00.

Where:

1406,57 is the weighted average of a circuit's price, considered the prices in the fourth column of the Table in Table 1 against the weighting figures of the second 
DOI: 10.14807/ijmp.v6i1.247

line of the Table in Table 2, the line referring to access. By doing the same with the other limiting resources, the limits of the table in Table 4 are attained.

Table 4: Table for the monthly physical and financial limit of each resource required for the activations.

\begin{tabular}{|c||r|c|}
\hline Type of Resource & $\begin{array}{c}\text { Limit for } \\
\text { each } \\
\text { Resource }\end{array}$ & $\begin{array}{l}\text { Limit for each } \\
\text { Resource (\$) }\end{array}$ \\
\hline \hline $\begin{array}{c}\text { Access (Last } \\
\text { Mile) }\end{array}$ & 1200 & $1.687 .884,00$ \\
\hline $\begin{array}{c}\text { Equipment for } \\
\text { Customer's Sites }\end{array}$ & 1534 & $2.157 .202,84$ \\
\hline $\begin{array}{c}\text { Network } \\
\text { Facilities }\end{array}$ & 400 & $562.736,00$ \\
\hline $\begin{array}{c}\text { Configuration of } \\
\text { Customer Network }\end{array}$ & 1776 & $2.497 .269,12$ \\
\hline Other Resources & 1152 & $1.620 .057,60$ \\
\hline
\end{tabular}

By building now the primary linear programming model applied to the problem proposed, and considering that all the data are now available, we get the following elements:

Object function: Max $\rightarrow 1545,65 \times 1+1856,36 \times 2+445,01 \times 3+1081,22 \times$ $4+1492,51 \times 5$

Once what is intended is to maximize the revenue from the prices of the circuits of each product (see Figure 1).

Restrictions to the Model:

R1) $998 \times 1+162 \times 2+132 \times 3+289 \times 4+108 \times 5 \leq 1.687 .884,00$;

R2) $1276 \times 1+206 \times 2+169 \times 3+369 \times 4+137 \times 5 \leq 2.157 .202,84$;

R3) $333 \times 1+54 \times 2+44 \times 3+96 \times 4+36 \times 5 \leq 562.736,00$;

R4) $1477 \times 1+239 \times 2+196 \times 3+428 \times 4+159 \times 5 \leq 2.497 .269,12$;

R5) $958 \times 1+155 \times 2+127 \times 3+277 \times 4+103 \times 5 \leq 1.620 .057,60$;

Once each type of limiting resource (see Figure 2) leads to a maximum limit of revenue acquisition resulting from circuit delivery, if analyzed separately from the others (see Table 2). 
R6) $x 1+x 2+x 3+x 4+x 5 \leq 3000$; maximum output capacity considered.

R7) $\times 1 \leq 5042$;

R8) $\times 2 \leq 816$;

R9) $\times 3 \leq 668$;

R10) $x 4 \leq 1459$;

$\mathrm{R} 11) \times 5 \leq 543 ;$

Once there is a finite set of circuits to be activated per month per type of network (product).

$\mathrm{R} 12$ a R16) $\times 1, \times 2, \times 3, \times 4, \times 5 \geq 0$. Since there are no negative activations (deliveries).

By submitting the Model to the SOLVER function in Microsoft's Excel application, the results shown in Figure 3 are attained.

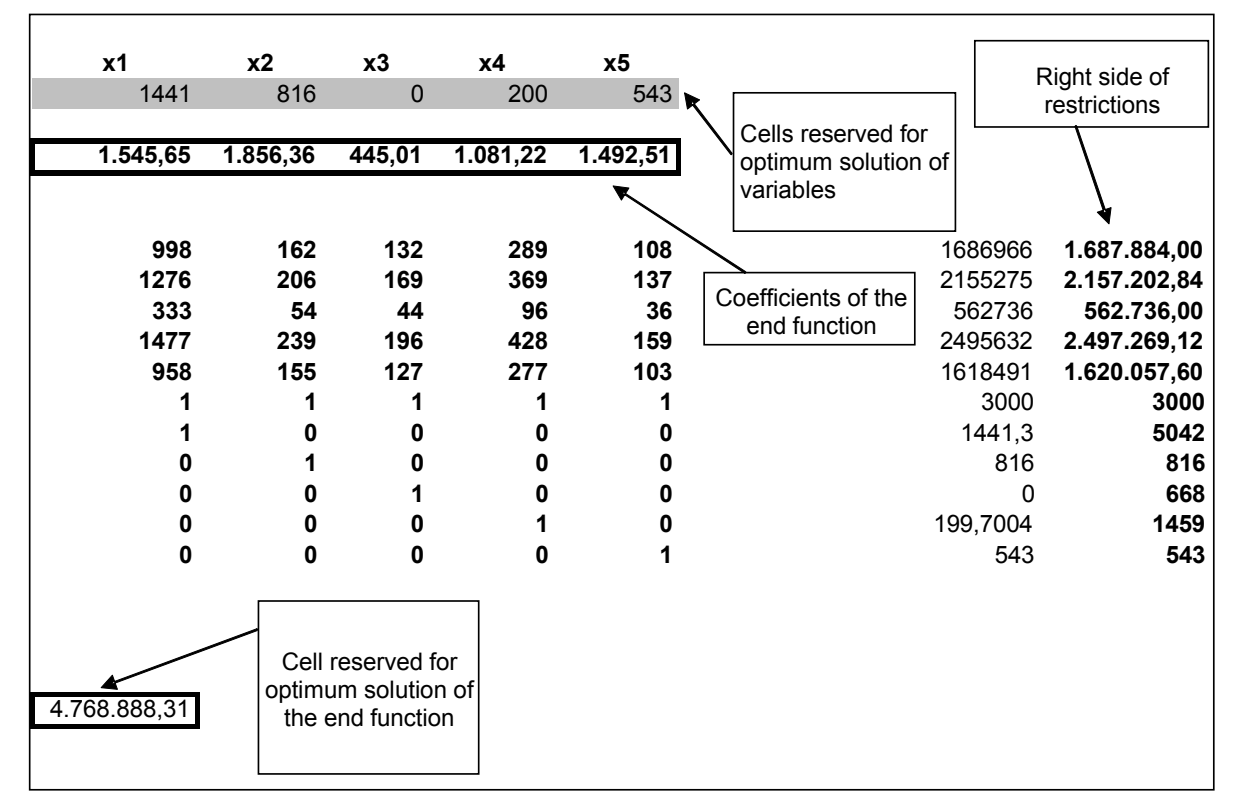

Figure 3: Output of Excel's SOLVER function.

The most outstanding points shown through the Excel's results are: the optimum outputs for the topic month would be the activation of 1,441 private telephone network circuit activations; 816 Internet network circuit activations; 200 low speed data network circuit activations; 543 high speed data network circuit activations; and postponing for the following period the activations of the Intranet network circuits, coming to a total of 3,000 activations monthly, amounting to a revenue of $\mathrm{R} \$ 4.768 .888,31$ for the company in the month of study. 
DOI: 10.14807/ijmp.v6i1.247

If the same model is calculated, bringing production up to 4,000 circuits a month, the distribution would be: Telephone networks 1,062, Internet 816, Intranet 120, Low Speed Data 1,459, High Speed Data 543, for a revenue of $R \$$ $5.597 .053,12$, leaving only the Telephone and Intranet circuits to be solved in over 30 days, as Figure 4 below shows.

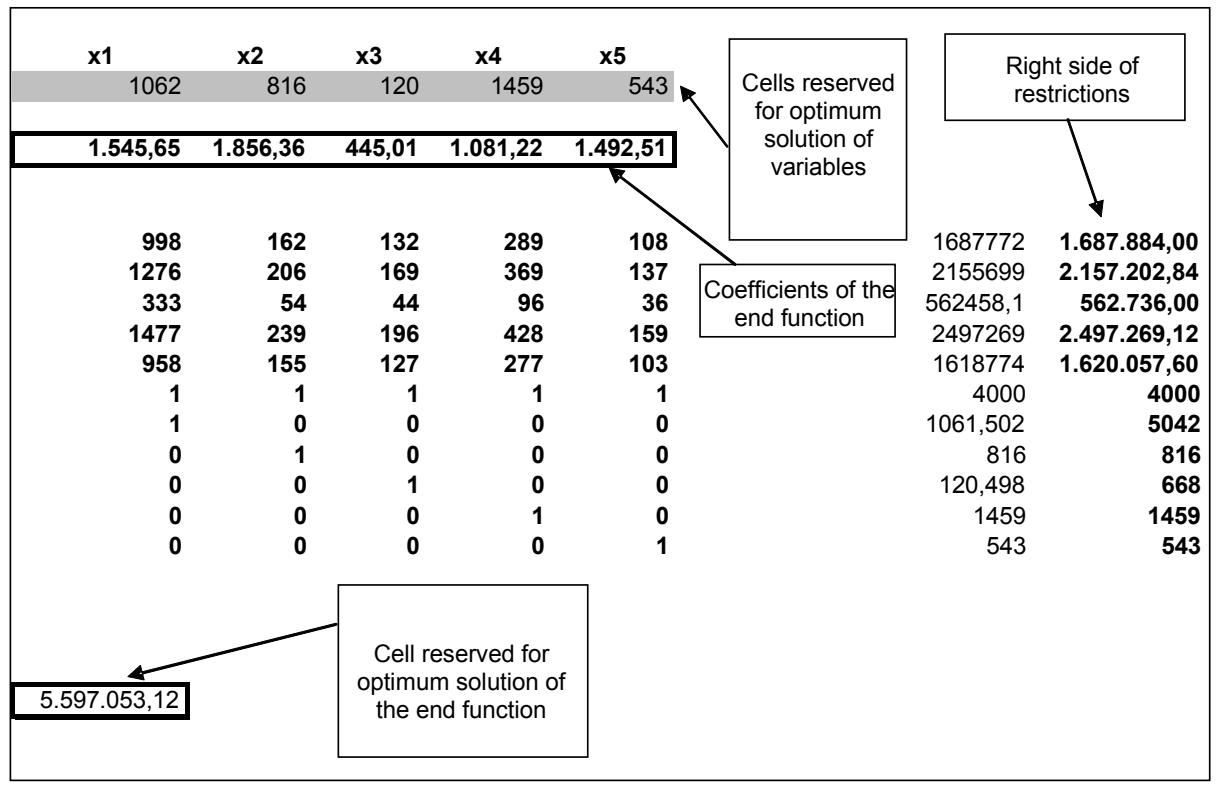

Figure 4: Output of Excel's SOLVER function.

\section{CONCLUSIONS AND RECOMMENDATIONS}

Some conclusions and recommendations can be taken from the information presented in this paper that help in the day-to-day of a telecommunications company working with activations (delivery) of customer corporate network circuits. First of all, the linear programming methodology proposes markers for the activations that further focus on parameters pre-defined by the company's management personnel.

As for the case presented in this paper, if average figures were to be used, by sharing the efforts of the activations teams per service, circuits would be activated that would add to earnings of $3000 \times R \$ 1.406,39=R \$ 4.219 .170,00$, which is $R \$$ $549.718,31$ lower than the revenue made available, by following the linear programming model. This means some revenue anticipation of roughly 2.5 million American dollars per year.

On the other hand, within a hyper-competitive environment, an output efficiency increase becomes urgent for any industry or service provider company. Through a Linear Programming Model, it gets easy to verify, for instance, that by 
increasing output capacity to 4,000 circuits per month, the revenue anticipation is increased by $(R \$ 5.597 .053,12-4.768 .888,31) R \$ 828.164,81$ monthly, and this can be enough reason for the company to hire further human resources to meet this revenue anticipation.

Finally, the utilization of statistics-based methodologies is recommended for output environments even in service providing, aiming at production maximization or even cost reduction. It is worth reminding that the model proposed here presents guidelines for the priorities, not ignoring other underlying factors in prioritizing an activation, such as a customer's urgent need or its category in a segmentation by size or importance. The same method used in this paper can guide the acquisition of resources for circuit activation, rental of third parties' access or vacation scheduling of the personnel involved in the provisioning, aiming at a more compatible distribution of human resources throughout the year regarding the demand for networks and services by customers.

\section{REFERENCES}

ACKOFF, R. L.; SASIENI, M. W. (1971) Pesquisa Operacional. Tradução de José L.M.Marques e Cláudio G. Reis. LTC, Rio de Janeiro.

ACKOFF, R. L. (1976) Planejamento Empresarial. Tradução de Marco Túlio de Freitas. LTC, Rio de Janeiro.

ANDRADE, E. L. (1990). Introdução à Pesquisa Operacional. LTC, Rio de Janeiro. BIERMAN Jr., H.; BONINI, C. P. (1973) Quantitative Analysis for Business Decisions. 4th edition, Richard D. Irwin, Illinois.

CARASTAN , J. T. (1993). Uma Análise da Utilidade da Programação Linear sob o Enfoque Contábil-Gerencial. Tese de Doutoramento defendida e aprovada na Faculdade de Economia, Administração e Contabilidade - USP, São Paulo.

CARLSON, C. K. (1988) "Information Management Approach and Support to Decision-Making". Information \& Management, North-Holland, Vol.15, Number 3, Oct, 88.

CORRAR, L. J.; TEÓPHILO, C. R. (2003). Pesquisa Operacional para Decisão em Contabilidade e Administração. Editora Atlas, Rio de Janeiro.

D’AVENI, R. (1995). Hipercompetição. Editora Campus, Rio de Janeiro.

YANKEE GROUP. [My Yankee Home Page]. Available for members in: http://www.yankeegroup.com/custom/search/search_results.jsp\#search_results , Jan 04th, 2005.

ZUMA, V.; CALDEIRA, A. M.; PACHECO, G. L.; MACHADO, M. A. S., GASSENFERTH, W. (2008), Métodos Quantitativos com EXCEL, Thomson Learning. 